Family Medicine and Community Health

\section{Delivery of healthcare provider's lifestyle advice and lifestyle behavioural change in adults who were overweight or obese in pre-diabetes management in the USA: NHANES (2013-2018)}

Mary Lynn Davis-Ajami, ${ }^{1}$ Zhiqiang Kevin Lu, ${ }^{2}$ Jun Wu (D ${ }^{3}$
To cite: Davis-Ajami ML, Lu ZK, Wu J. Delivery of healthcare provider's lifestyle advice and lifestyle behavioural change in adults who were overweight or obese in pre-diabetes management in the USA: NHANES (2013-2018). Fam Med Com Health 2021;9:e001139. doi:10.1136/fmch-2021-001139

- Additional supplemental material is published online only. To view, please visit the journal online (http://dx.doi.org/10. 1136/fmch-2021-001139).

\section{Check for updates}

\section{Author(s) (or their} employer(s)) 2021. Re-use permitted under CC BY-NC. No commercial re-use. See rights and permissions. Published by BMJ.

${ }^{1}$ Department of Science of Nursing Care, Indiana University School of Nursing, Indianapolis, Indiana, USA

${ }^{2}$ Department of Clinical Pharmacy and Outcomes Sciences, University of South Carolina College of Pharmacy, Columbia, South Carolina, USA ${ }^{3}$ Department of Pharmaceutical and Administrative Sciences, Presbyterian College School of Pharmacy, Clinton, South Carolina, USA

Correspondence to Dr Jun Wu; jwu@presby.edu

\section{ABSTRACT}

Objective The purpose of this study is to examine the association between delivery of healthcare provider's advice about lifestyle management and lifestyle behavioural change in pre-diabetes management in adults who were overweight or obese.

Design This cross-sectional study included adults with body mass index $(\mathrm{BMI}) \geq 25 \mathrm{~kg} / \mathrm{m}^{2}$ and reporting pre-diabetes in USA. Outcomes included the prevalence of receiving provider's advice on lifestyle management and patterns of practicing lifestyle change. The association between delivery of provider's advice and lifestyle-related behavioural change in pre-diabetes management was examined.

Setting US Continuous National Health and Nutrition Examination Survey (2013-2018).

Participants A total of 1039 adults with $\mathrm{BMI} \geq 25 \mathrm{~kg} / \mathrm{m}^{2}$ reported pre-diabetes.

Results Of eligible adults with pre-diabetes, $76.8 \%$ received provider's advice about lifestyle change. The advice group showed higher proportions of ongoing lifestyle change than no advice group, including weight reduction/control ( $80.1 \%$ vs $70.9 \%, p=0.018)$, exercise (70.9\% vs $60.9 \%, p=0.013)$ and diet modifications $(83.8 \%$ vs $61.8 \%, p<0.001)$. After adjustment, those receiving provider's advice were more likely to increase exercise (OR $1.63,95 \% \mathrm{Cl} 1.12$ to 2.38$)$ and modify diet (OR $3.0,95 \% \mathrm{Cl}$ 1.82 to 4.96$)$.

Conclusion Over $75 \%$ of US adults who were overweight or obese and reported pre-diabetes received healthcare provider's advice about reducing the risk of diabetes through lifestyle change. Provider's advice increased the likelihood of lifestyle-related behavioural change to exercise and diet.

\section{INTRODUCTION}

Pre-diabetes increases the risk of developing type 2 diabetes and cardiovascular diseases (CVD). ${ }^{1}$ More than one-third of US adults have pre-diabetes, although only about $20 \%$ are aware that they have pre-diabetes. ${ }^{2}$ For the 88 million US adults with pre-diabetes, approximately $11 \%$ will progress to type 2 diabetes annually. ${ }^{3}$ Lifestyle interventions,

\begin{tabular}{l} 
KEY POINTS \\
\hline QUESTION \\
$\Rightarrow$ How did US health professionals deliver advice \\
about lifestyle management to adults who were \\
overweight or obese in pre-diabetes management \\
and how did their advice change lifestyle behaviour? \\
FINDING \\
$\Rightarrow$ More than $75 \%$ of adults who were overweight or \\
obese received a provider's advice for pre-diabetes \\
management to reduce the risk for diabetes through \\
lifestyle change. Over 70\% of those who received \\
lifestyle advice in the study reported that they fol- \\
lowed the provider's advice. \\
MEANING \\
$\Rightarrow$ Providers focused on a high-risk population to de- \\
liver advice about type 2 diabetes prevention and \\
management through lifestyle change. This focus \\
translated clinical evidence into primary care prac- \\
tice advice giving. However, Hispanics were more \\
likely to receive provider's advice than non-Hispanic \\
whites. Primary care providers should take the op- \\
portunity to understand their patients' behaviour \\
and identify barriers to pre-diabetes management.
\end{tabular}

including weight loss, nutrition and physical activity, can effectively prevent or delay the occurrence of diabetes, as evidenced by several large diabetes prevention programmes. ${ }^{4-6}$ The Diabetes Prevention Programme demonstrated that intensive lifestyle change could reduce the progression from pre-diabetes to type 2 diabetes by $58 \%$ over 3 years. ${ }^{4}$ In the USA, the Diabetes Prevention Programme Outcomes Study showed that long-term lifestyle change reduced the risk for type 2 diabetes by $34 \%$ at ten years and $27 \%$ at 15 years. $^{78}$

The data showing sustained reductions in progression to type 2 diabetes using lifestyle 
interventions is compelling. Yet, broad adoption of implementing pre-diabetes treatment guidelines in clinical practice is lacking. ${ }^{9-12}$ When comparing those who know they have pre-diabetes to those with normal fasting serum glucose, those with pre-diabetes were more likely to report positive behavioural change such as weight control, increased exercise and fat and caloric reduction. ${ }^{13}$ Yet less than $25 \%$ of patients with pre-diabetes reported having received lifestyle change advice during an office visit with their medical providers. ${ }^{9}$ There is a gap in our knowledge about the associations between the evidence-based practice guideline supporting lifestyle change, physician utilisation of that the guideline to provide advice during office visits and subsequent change in patient behaviour.

Obesity has been identified as a risk factor for diabetes. ${ }^{14}$ A meta-analysis combining 11 prospective cohort studies found that healthy adults with obesity and unhealthy adults with obesity were 4 times and 8.9 times more likely respectively to develop type 2 diabetes than healthy normal weight adults. ${ }^{15}$ However, knowledge about the adoption of lifestyle management advice for patients who are overweight or obese in pre-diabetes management is limited. It remains to be determined whether the healthcare provider's advice about lifestyle management was delivered to this high-risk population as expected. We need more robust information about whether patients with obesity and pre-diabetes follow their provider's advice regarding lifestyle practices known to mitigate the risk of developing diabetes. Understanding the patterns associated with receiving lifestyle management advice from health professionals and patient behaviour associated with adopting those recommendations could help identify socioeconomic disparities of and barriers to providing patient centric lifestyle interventions that prevent the progression from pre-diabetes to diabetes. This study aimed to (1) examine the prevalence and patterns of receiving a physician or other healthcare provider's advice to change lifestyle behaviours in adults who were overweight or obese and reported pre-diabetes and (2) assess whether the provider's advice influenced lifestyle behaviours in this high-risk population.

\section{METHODS}

\section{Study design and data source}

This retrospective cross-sectional study accessed the publicly available Continuous National Health and Nutrition Examination Survey (NHANES) data for years 2013-2018. ${ }^{16}$ NHANES is designed and conducted by the National Center for Health Statistics to assess the health and nutritional status in the US civilian, noninstitutionalised population. ${ }^{16}$ NHANES collects data through interviews and physical examination covering 2 years in a stratified and multistage probability sample.

\section{Study sample}

This study sample was derived by pooling three cycles of the Continuous NHANES data (2013-2014, 2015-2016 and
2017-2018). Participants who met the following criteria were included: (1) aged $\geq 20$ years; (2) told by a doctor or other professional that they had pre-diabetes, impaired fasting glucose, impaired glucose tolerance or borderline diabetes and (3) body mass index (BMI) $\geq 25 \mathrm{~kg} / \mathrm{m}^{2}$. Participants excluded from the study sample met these criteria: (1) pregnant; (2) told by a doctor or other health professional that they have diabetes or (3) had missing responses to the questions examined in this study. The participants with missing responses accounted for $1 \%$ of the study sample.

The study sample was divided into two groups: (1) providers' advice group (ie, the participants were told by a doctor or other health professional to control or lose weight, increase physical activity or exercise or reduce the amount of fat or calories in diet) and (2) no-advice group (ie, the participants were not told to change their lifestyle by losing weight, exercise and through diet).

\section{Outcome measures}

The primary outcome was the participants' lifestyle behaviour, as measured by the responses to survey questions regarding whether participants changed their lifestyle by controlling or losing weight, increasing physical activity or exercise, or reducing the amount of fat or calories in the diet, respectively. The patterns of providers' advice and participants' behaviour of lifestyle change were described.

\section{Characteristics of study sample}

The study assessed BMI, age, race, gender, education, income, health insurance, access to healthcare, activity limitation, family history of diabetes and history of CVDs to reflect the characteristics of the study sample. These variables were also included in the regression analysis as covariates for adjustment.

Overweight was defined by BMI $\left(25-29.9 \mathrm{~kg} / \mathrm{m}^{2}\right)$ and obesity was defined by BMI $\geq 30 \mathrm{~kg} / \mathrm{m}^{2}$. ${ }^{17}$ The definitions of the following variables were from NHANES documentations. ${ }^{16}$ Family income level was measured by the NHANES family monthly poverty level index variable that is a ratio of the monthly family income to the US federal poverty line adjusted to account for family size. Access to healthcare was measured by the response to the NHANES survey question, 'Is there a place that you usually go when you are sick or need advice about health?' Activity limitation was defined as participant-reported limitations caused by long-term physical, mental or emotional problems or illness. History of CVD was defined as 'yes CVD' when the participants were told by a doctor or other health professional that they had congestive heart failure, coronary heart disease, heart attack, stroke, hypertension or hyperlipidaemia.

\section{Data analysis}

For the sample of overweight and obese adults with prediabetes, this study used $\chi^{2}$ tests to compare characteristics and lifestyle behavioural change between those who 
Table 1 Characteristics of adults (BMI $\geq 25 \mathrm{~kg} / \mathrm{m}^{2}$ ) with prediabetes by health professional's advice received to reduce diabetes risk $(n=1039)$

\begin{tabular}{|c|c|c|c|}
\hline \multirow[b]{2}{*}{ Characteristics } & $\begin{array}{l}\text { Health } \\
\text { professionals' } \\
\text { advice }(n=798)\end{array}$ & $\begin{array}{l}\text { No advice } \\
(n=241)\end{array}$ & \multirow[b]{2}{*}{ P value* } \\
\hline & $\begin{array}{l}\text { n } \\
\text { (weighted \%) }\end{array}$ & $\begin{array}{l}\text { n } \\
\text { (weighted \%) }\end{array}$ & \\
\hline Age (years) & & & 0.059 \\
\hline $20-44$ & $214(28.8)$ & 75 (32.9) & \\
\hline $45-64$ & $366(45.8)$ & $81(33.4)$ & \\
\hline $65+$ & $218(25.3)$ & $85(33.7)$ & \\
\hline Gender (female) & $495(58.4)$ & $122(51.2)$ & 0.229 \\
\hline $\mathrm{BMI}\left(\mathrm{kg} / \mathrm{m}^{2}\right)$ & & & $<0.001$ \\
\hline $25-29.9$ & $251(32.3)$ & $141(61.1)$ & \\
\hline $30-34.9$ & 247 (30.9) & $55(20.0)$ & \\
\hline$\geq 35$ & $300(36.8)$ & 45 (18.9) & \\
\hline Race & & & 0.138 \\
\hline Non-Hispanic white & $250(62.5)$ & $106(71.0)$ & \\
\hline Non-Hispanic black & $173(10.4)$ & $40(7.7)$ & \\
\hline Hispanic & $265(18.4)$ & $63(14.9)$ & \\
\hline Other & $110(8.8)$ & $32(6.4)$ & \\
\hline Education & & & 0.327 \\
\hline Less than high school & $158(9.6)$ & $41(10.6)$ & \\
\hline High school/GED & $162(21.8)$ & $66(25.8)$ & \\
\hline $\begin{array}{l}\text { Some college/associate } \\
\text { degree }\end{array}$ & $279(35.6)$ & $71(27.6)$ & \\
\hline $\begin{array}{l}\text { College graduate or } \\
\text { above }\end{array}$ & $197(33.0)$ & $63(36.0)$ & \\
\hline Family income & & & 0.284 \\
\hline Poor & 227 (19.6) & 71 (18.6) & \\
\hline Low & $189(18.1)$ & 47 (15.2) & \\
\hline Medium & 177 (23.9) & $50(18.8)$ & \\
\hline High & $205(38.4)$ & $73(47.4)$ & \\
\hline Health insurance & & & 0.673 \\
\hline Private & $363(41.6)$ & $116(45.7)$ & \\
\hline Public & $325(46.5)$ & $85(42.0)$ & \\
\hline Uninsured & $110(11.9)$ & $40(12.3)$ & \\
\hline Routine place for healthcare & $722(90.3)$ & 194 (76.9) & 0.008 \\
\hline Activity limitation & $299(32.8)$ & 63 (18.6) & 0.004 \\
\hline Family history of diabetes & $360(46.9)$ & $102(47.5)$ & 0.926 \\
\hline History of CVD & 628 (76.9) & $141(58.1)$ & $<0.001$ \\
\hline
\end{tabular}

*The $p$ values were calculated by $\chi 2$ tests.

$\mathrm{BMI}$, body mass index; CVD, cardiovascular disease; GED, general education development.

received a provider's advice and those who did not. Multivariable logistic regression was performed to identify significant factors associated with receiving the providers' advice about lifestyle changes. The dependent variable in this logistic regression was whether receiving providers' advice (yes vs no). Independent variables were participants' demographic and health characteristics in table 1. If racial disparity in receiving the provider's advice was

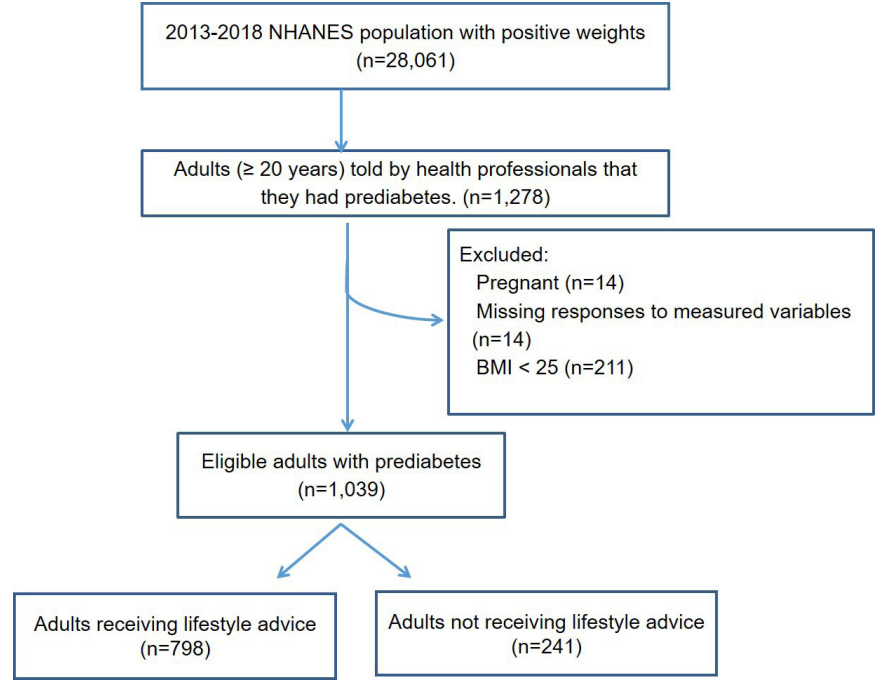

Figure 1 Study sample of eligible adults with pre-diabetes. BMI, body mass index; NHANES, National Health and Nutrition Examination Survey.

identified in the logistic regression, subgroup analysis was performed to compare advice delivery patterns between different races.

The multivariable logistic regression also examined the effect of the providers' advice on participants' practice of lifestyle change. The dependent variables in three logistic regression models were reducing fat or calorie intake (yes vs no), increasing physical activity or exercises (yes vs no) and controlling or losing weight (yes vs no), respectively. The primary independent variable in the three logistic regression models was provider's advice (yes vs no). Participants' demographics, insurance status, activity limitation, family history of diabetes and history of CVD were included in the regression as covariates for adjustment.

With the consideration of the complex survey design, sample interview weights were constructed and applied to all analyses to get national estimates for the US population. ${ }^{18}$ The statistical significance was set at $\mathrm{p}<0.05$. SAS V.9.4 was used for all analyses.

\section{RESULTS}

A total of 1039 eligible adults with $\mathrm{BMI} \geq 25 \mathrm{~kg} / \mathrm{m}^{2}$ reported pre-diabetes, representing 16.6 million individuals in the USA, and were included in the study sample (figure 1). Of those, $76.8 \%(n=798)$ received a providers' advice and $90 \% \quad(n=935)$ reported lifestyle change to reduce the risk for diabetes. In table 1 , compared with the no-advice group, participants receiving a provider's advice for lifestyle modification showed significantly higher proportions in the following characteristics: obesity $(76.7 \%$ vs $38.9 \%, \mathrm{p}<0.001)$, having a routine place for healthcare $(90.3 \%$ vs $76.9 \%, \mathrm{p}=0.01)$ and reporting activity limitation $(32.8 \%$ vs $18.6 \%, \mathrm{p}<0.001)$ and history of CVD (76.9\% vs $58.1 \%$, p<0.001). 


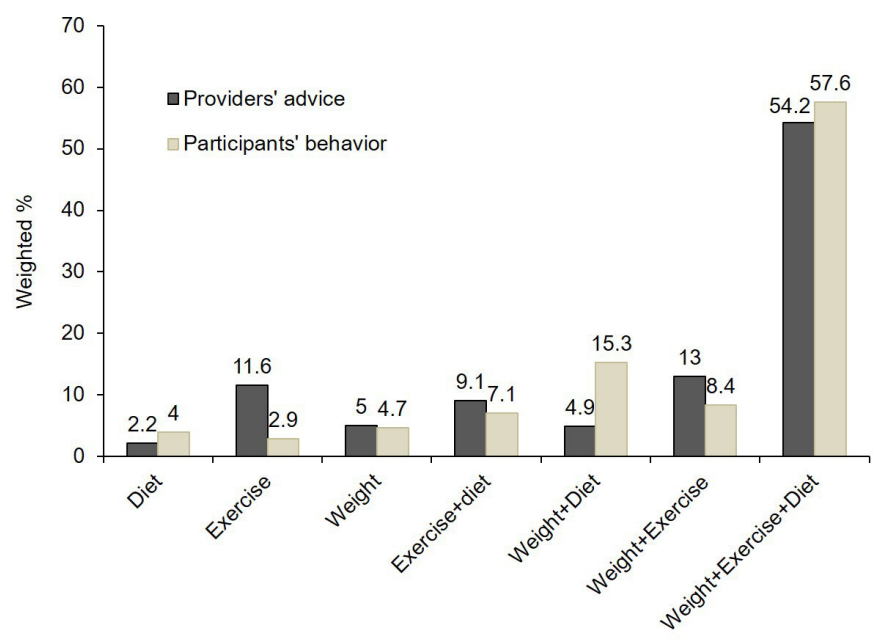

Figure 2 Patterns of lifestyle modification advice provided by healthcare providers $(n=789)$ and participants' practice $(n=739)$ in lifestyle change to reduce diabetes risk diet: reducing amount of fat or calories in diet; exercise: increasing physical activity or exercise; weight: control or weight loss.

Figure 2 displays the overall patterns of advice provided by providers and participants' practice of lifestyle change to reduce diabetes risk. Health professionals provided advice of lifestyle change to $76.8 \%$ of adults with BMI $\geq 25 \mathrm{~kg}$ / $\mathrm{m}^{2}$ and reporting pre-diabetes. Nearly $55 \%$ of those were advised to change all three aspects of lifestyle: (1) controlling or losing weight, (2) increasing exercise and (3) reducing calorie intake. Advice of changing two aspects of lifestyle was provided to $27 \%$ of the adults. Among those receiving advice, 93.2\% reported lifestyle change on at least one aspect. Nearly $58 \%$ of the adults reported lifestyle change on all three aspects. Over one-third of the adults reported lifestyle change on two aspects.

Table 2 presents significant factors associated with receiving health professional's advice on lifestyle change in adults with $\mathrm{BMI} \geq 25 \mathrm{~kg} / \mathrm{m}^{2}$ and pre-diabetes. Overall, obesity (vs overweight), Hispanic (vs White), access to healthcare and history of CVD increased the likelihood of receiving advice from health professionals on all three aspects of lifestyle change. Participants with activity limitation were two times more likely to be advised to increase exercise. Those with college or above education were 2.4 or 2.5 times more likely to receive advice on weight loss than those with education less than high school. Online supplemental table 1 shows the full results of multivariable logistic regression on likelihood of receiving providers' advice on lifestyle change. In the subgroup analysis (table 3), compared with non-Hispanic whites, Hispanic Americans showed higher proportions of receiving provider's advice on diet $(66.2 \%$ vs $46.1 \%, \mathrm{p}<0.001)$, exercise $(75.6 \%$ vs $60.7 \%, \mathrm{p}<0.001)$ and weight control $(61.9 \%$ vs $52.3 \%$, $\mathrm{p}<0.013)$.

Table 2 Significant factors associated with receiving health professional's advice on lifestyle change in overweight and obese adults with pre-diabetes $(n=1039)$

\begin{tabular}{|c|c|c|c|}
\hline \multirow[b]{2}{*}{ Independent variable } & \multicolumn{3}{|c|}{ Dependent variable: receiving advice, OR $(95 \% \mathrm{Cl})$} \\
\hline & Diet & Exercise & Losing weight \\
\hline \multicolumn{4}{|l|}{ BMI } \\
\hline Obese & 2.28 (1.51 to 3.43 ) & 2.10 (1.31 to 3.38 ) & 4.35 (3.01 to 6.29 ) \\
\hline \multicolumn{4}{|l|}{ Race } \\
\hline Hispanic & 2.14 (1.49 to 3.07 ) & 1.98 (1.28 to 3.06$)$ & 1.73 (1.06 to 2.81 ) \\
\hline Other & 1.48 (0.89 to 2.46$)$ & 2.43 (1.15 to 5.16$)$ & 1.00 (0.55 to 1.79$)$ \\
\hline \multicolumn{4}{|l|}{ Education } \\
\hline Less than high school & - & - & 1.00 \\
\hline High school/GED & - & - & 1.12 (0.63 to 1.99 ) \\
\hline No & 1.00 & 1.00 & 1.00 \\
\hline Yes & 2.43 (1.23 to 4.83$)$ & 2.32 (1.10 to 4.93$)$ & 2.72 (1.44 to 5.12 ) \\
\hline \multicolumn{4}{|l|}{ Activity limitation } \\
\hline No & - & 1.00 & - \\
\hline Yes & - & 1.99 (1.22 to 3.24$)$ & - \\
\hline \multicolumn{4}{|l|}{ History of CVD } \\
\hline No & 1.00 & 1.00 & 1.00 \\
\hline Yes & 2.37 (1.52 to 3.67$)$ & 2.54 (1.46 to 4.42$)$ & 2.00 (1.21 to 3.33 ) \\
\hline
\end{tabular}

BMI, body mass index; CVD, cardiovascular disease; GED, general education development. 
Table 3 Receiving health provider's advice on lifestyle change in Hispanic and non-Hispanic white Americans with pre-diabetes $(n=684)$

\begin{tabular}{|c|c|c|c|}
\hline & $\begin{array}{l}\text { Hispanic } \\
(n=356) \\
n \text { (weight \%) }\end{array}$ & $\begin{array}{l}\text { Non-Hispanic } \\
\text { white }(n=328) \\
\text { n (weighted \%) }\end{array}$ & P value* \\
\hline Diet & 217 (66.2) & $164(46.1)$ & $<0.001$ \\
\hline Exercise & $248(75.6)$ & $216(60.7)$ & $<0.001$ \\
\hline Controlling/losing weight & $203(61.9)$ & $186(52.3)$ & 0.013 \\
\hline
\end{tabular}

${ }^{\star}$ The $p$ values were calculated by $\chi 2$ tests.

Table 4 shows whether providers' advice facilitated participants' practice of lifestyle change. The participants who received lifestyle change advice reported higher proportions of ongoing lifestyle changes than those in the no-advice group, including changes in diet $(83.8 \%$ vs $61.8 \%$, $\mathrm{p}<0.001)$, exercise $(70.9 \%$ vs $60.9 \%, \mathrm{p}=0.013)$ and weight reduction/ control $(80.1 \%$ vs $70.9 \%$, $\mathrm{p}=0.018)$. After adjusting for participants' demographic and health characteristics, those in the advice group were more likely to reduce their fat or calorie intake (OR 3.00, 95\% CI 1.82 to 4.96 ) and increase physical activity or exercise (OR 1.63, 95\% CI 1.12 to 2.38). The providers' advice did not affect the participants' behaviour for weight reduction/control significantly (OR 1.36, 95\% CI 0.86 to 2.15). Online supplemental table 2 shows the full results of multivariable logistic regression on the association between providers' advice and participants' practice of lifestyle change.

\section{DISCUSSION}

This study reports three major findings. First, more than $75 \%$ of adults who were overweight or obese and reported pre-diabetes received a provider's advice to reduce the risk for diabetes through lifestyle change, much higher than the prevalence $(23 \%)$ reported in a general pre-diabetes

Table 4 Association between heath care provider's advice delivery and participants' behaviour of lifestyle change to reduce the risk for diabetes $(n=1039)$

\begin{tabular}{|c|c|c|}
\hline & \multicolumn{2}{|c|}{ Reducing amount of fat or calories in diet } \\
\hline & n (weighted \%) & Adjusted OR (95\% Cl) \\
\hline \multicolumn{3}{|c|}{ Provider's advice received } \\
\hline No $(n=450)$ & $267(61.8)$ & 1.00 \\
\hline Yes $(n=589)$ & $493(83.8)$ & 3.00 (1.82 to 4.96$)$ \\
\hline$P$ value & $<0.001$ & $<0.001$ \\
\hline \multicolumn{3}{|c|}{ Increasing physical activity or exercise } \\
\hline No $(n=323)$ & $190(60.9)$ & 1.00 \\
\hline Yes $(n=716)$ & $488(70.9)$ & $1.63(1.12$ to 2.38$)$ \\
\hline$P$ value & 0.013 & 0.012 \\
\hline \multicolumn{3}{|c|}{ Controlling or losing weight } \\
\hline No $(n=448)$ & 309 (70.9) & 1.00 \\
\hline Yes $(n=591)$ & $479(80.1)$ & $1.36(0.86$ to 2.15$)$ \\
\hline$P$ value & 0.018 & 0.178 \\
\hline
\end{tabular}

population not limited to overweight or obesity status. ${ }^{9}$ Second, a disparity between Hispanics and non-Hispanic whites was identified in this study's population in regard to receiving provider's advice about lifestyle management. Finally, receiving advice from a provider significantly increased the likelihood of lifestyle change. Over $70 \%$ of those who received lifestyle advice in the study reported that they followed the provider's advice.

Lifestyle interventions have been shown to be effective in reducing the risk of diabetes. ${ }^{419}{ }^{20}$ However, a previous study indicated that less than $25 \%$ of a general adult population of pre-diabetes patients received provider's advice about lifestyle change during office visits. ${ }^{9}$ This study found a much higher prevalence for receiving lifestyle management from health providers $(76.5 \%)$ when the population of interest was limited to those who were overweight and obese. The results suggest that the gap between pre-diabetes treatment guidelines and clinical practice was reduced in people who were overweight or obese. Health professionals might pay more attention to reduce the risk of diabetes in a high-risk population. However, in this study, one quarter of adults with a BMI $\geq 25 \mathrm{~kg} / \mathrm{m}^{2}$ and pre-diabetes did not receive provider's advice about lifestyle change, a finding that becomes more concerning when the prevalence of diabetes screening in ambulatory care is considered. A study using the US National Ambulatory Medical Care Survey from years 2012-2015 reported that fewer than $15 \%$ of adults with BMI $\geq 25 \mathrm{~kg} / \mathrm{m}^{2}$ and pre-diabetes indicators were screened for diabetes. ${ }^{10}$ With the growth of pre-diabetes prevalence in the USA, efforts have been made to increase the awareness of pre-diabetes through treatment guidelines ${ }^{1}$ and the National Diabetes Education Programme. ${ }^{21}$ However, screening for pre-diabetes and delivering pre-diabetes management are still a challenge in clinical practice for the entire US population. ${ }^{910}$

This study identified a racial disparity between Hispanics and non-Hispanic whites with pre-diabetes related to receiving provider advice about lifestyle change. Overall, Hispanic Americans were more likely to receive lifestyle management advice from their providers. The subgroup analysis indicated that the biggest difference occurred in the advice on diet change, where $66 \%$ of Hispanic adults received advice to reduce fat or calories intake vs $46 \%$ of non-Hispanic whites $(\mathrm{p}<0.001)$. In the USA, the prevalence of diabetes in Hispanic Americans is $17 \%$, higher than non-Hispanic whites $(8 \%) .^{22}$ The higher prevalence of diabetes in Hispanic population might make health professionals more likely to address lifestyle change management to this population with high risk of developing diabetes. Research regarding Western diet acculturation and traditional Hispanic food choices may have influenced the increased likelihood to discuss dietary factors with Hispanic patients. ${ }^{23}{ }^{24}$ The increased focus on lifestyle advice compared with non-Hispanic white adults may be influenced by provider's perceptions about reported low levels of physical activity in Hispanic Americans. ${ }^{25}$

This study found that those receiving the provider's advice were more likely to report reducing fat or calories 
intake and increasing exercise than those without provider advice. The results suggest providers advice would influence pre-diabetes lifestyle management. Providers often serve as a major resource to help patients learn about diabetes management. ${ }^{26}$ Patients may view the communication from their provider as a more trusted, reliable and effective source of information to address their specific health concerns. ${ }^{27}$ Patients may be more inclined to engage in lifestyle change after getting instructions from their provider than from developing self-awareness about pre-diabetes or knowledge obtained from other sources. However, more studies are needed to examine the long-term effect of health provider's advice on quality, engagement and outcomes associated with pre-diabetes management in the overweight and obese population.

Whether patients follow a provider's advice after an office visit is another concern in pre-diabetes management. Adherence to lifestyle change is critical to reduce the risk of type 2 diabetes. The results showed that after receiving a provider's advice, over $80 \%$ of people reported reducing fat or calories intake and controlling or losing weight, and $70 \%$ reported increasing physical activity or exercise. The provider's advice or the person's perceived diabetes risk could contribute to the lifestyle change behaviour. Abel et als study indicated that supportive factors would help patients with pre-diabetes to make dietary changes, such as determination not to develop diabetes, clear information and manageable strategies and supportive relationship. ${ }^{28}$ Additional nutrition care is important to support dietary change in pre-diabetes management. ${ }^{29}$ Further studies are needed to examine the long-term adherence to lifestyle management to determine factors that sustain lifestyle change to reduce the risk of diabetes in overweight and obese populations.

This study provides important implications for prediabetes management in primary care. Compared with previous research assessing the general adult population, the gap between clinical guidelines regarding lifestyle style change in pre-diabetes treatment and real-world practice was reduced significantly in the overweight and obese population. However, inequitable access to diabetes care presents a major barrier to getting advice about diabetes disease management from a primary care provider. ${ }^{30}$ Addressing access to care may improve the dissemination of important lifestyle, diet and disease management information to vulnerable populations with type 2 diabetes. Delivering equitable population-based lifestyle interventions remains challenging in preventing and controlling type 2 diabetes. Primary care providers play an essential role in motivating patients to change their lifestyle to manage pre-diabetes. Patient-centred care has been proposed as a successful approach in diabetes management. ${ }^{31}{ }^{32}$ Primary care providers should take the opportunity to understand their patients' behaviour and identify barriers to pre-diabetes management. This would help personalise lifestyle intervention delivery, improve the quality of health advice and achieve desired treatment goals.

\section{Limitations}

First, all eligible respondents included in this study represented US adults who self-reported they were aware of having pre-diabetes. The findings of this study may not be generalised to the US population whose pre-diabetes diagnosis was determined by laboratory test values. ${ }^{33}$ Second, the results from NHANES data reflected a snapshot in time of participants' behaviour to prevent or delay type 2 diabetes. It is unknown whether receiving a provider's advice translated into actual behavioural change or long-term adherence to improved approaches to healthy lifestyle choices. The results should be interpreted with some caution as there may be discrepancies between what the respondent reported versus how well they followed the provider's advice. Also, this study did not imply any causal relationships between a provider's lifestyle management advice and adopting all or portions of that advice or between a provider's advice and successful prevention of pre-diabetes disease progression. Third, the details of providers' advice, such as duration and intensity, were not available in the NHANES. Variations in delivering lifestyle management advice might exist among the providers; however, this study could not measure the quality of the providers' advice about lifestyle factors on pre-diabetes management. Additionally, the providers' specialties were unknown, so the differences in lifestyle management delivery patterns among health providers with various specialties were not examined. Finally, the effects of the providers' advice on treatment outcomes (eg, glucose control) were not assessed. This study suggests that the providers' advice increased the likelihood of implementing lifestyle change to manage pre-diabetes; however, further research is needed to compare the health outcomes associated with lifestyle changes in those receiving a provider's advice vs those who did not receive advice.

\section{CONCLUSION}

Over $75 \%$ of US adults with BMI $\geq 25$ and pre-diabetes received advice about reducing the risk of diabetes through lifestyle change from their healthcare provider. This is a much greater percentage of persons to be given advice about pre-diabetes lifestyle approaches to pre-diabetes management than for those with normal weight. Moreover, our findings show that providers focused more on the Hispanic patient population who were overweight or obese than their White counterparts. This finding aligns with the greater risk Hispanic patients have of progressing to diabetes when weight is a factor. There is room for improvement to show equity across all weight categories, as racial backgrounds when giving advice about lifestyle change among adults who are overweight or obese with pre-diabetes. Finally, the results show that healthcare provider's advice increased the likelihood of lifestyle-related behavioural change to exercise and diet.

Acknowledgements The authors wish to acknowledge Mary Hannah's work to help edit the manuscript. 
Contributors MLD-A and JW contributed to the concept of the study. MLD-A, ZKL and JW contributed to the analysis and interpretation of the data. MLD-A and JW contributed to the drafting of the manuscript. All authors contributed to the critical revision of the manuscript and approved the final version for publication and took responsibility for the accuracy and integrity of the study. JW is responsible for the overall content as the guarantor.

Funding The authors have not declared a specific grant for this research from any funding agency in the public, commercial or not-for-profit sectors.

Competing interests None declared.

Patient consent for publication Not applicable.

Ethics approval This study was approved by Institutional Review Boards of Presbyterian College.

Provenance and peer review Not commissioned; externally peer reviewed

Data availability statement Data are available in a public, open access repository. NHANES data is available for public use from https://www.cdc.gov/nchs/nhanes/ about_nhanes.htm.

Supplemental material This content has been supplied by the author(s). It has not been vetted by BMJ Publishing Group Limited (BMJ) and may not have been peer-reviewed. Any opinions or recommendations discussed are solely those of the author(s) and are not endorsed by BMJ. BMJ disclaims all liability and responsibility arising from any reliance placed on the content. Where the content includes any translated material, BMJ does not warrant the accuracy and reliability of the translations (including but not limited to local regulations, clinical guidelines, terminology, drug names and drug dosages), and is not responsible for any error and/or omissions arising from translation and adaptation or otherwise.

Open access This is an open access article distributed in accordance with the Creative Commons Attribution Non Commercial (CC BY-NC 4.0) license, which permits others to distribute, remix, adapt, build upon this work non-commercially, and license their derivative works on different terms, provided the original work is properly cited, appropriate credit is given, any changes made indicated, and the use is non-commercial. See: http://creativecommons.org/licenses/by-nc/4.0/.

\section{ORCID iD}

Jun Wu http://orcid.org/0000-0003-4098-3833

\section{REFERENCES}

1 American Diabetes Association. 2. Classification and Diagnosis of Diabetes: Standards of Medical Care in Diabetes-2020. Diabetes Care 2020;43:S14-31.

2 Centers for Disease Control and Prevention. Prediabetes - Your chance to prevent type 2 diabetes. Available: https://www.cdc.gov/ diabetes/basics/prediabetes.html [Accessed 22 Dec 2020].

3 Centers for Disease Control and Prevention (CDC). Awareness of prediabetes--United States, 2005-2010. MMWR Morb Mortal Wkly Rep 2013;62:209-12.

4 Knowler WC, Barrett-Connor E, Fowler SE, et al. Reduction in the incidence of type 2 diabetes with lifestyle intervention or metformin. N Engl J Med 2002;346:393-403.

5 Lindström J, llanne-Parikka P, Peltonen M, et al. Sustained reduction in the incidence of type 2 diabetes by lifestyle intervention: follow-up of the Finnish diabetes prevention study. Lancet 2006;368:1673-9.

6 Li G, Zhang P, Wang J, et al. Cardiovascular mortality, all-cause mortality, and diabetes incidence after lifestyle intervention for people with impaired glucose tolerance in the dA Qing diabetes prevention study: a 23-year follow-up study. Lancet Diabetes Endocrinol 2014:2:474-80.

7 Diabetes Prevention Program Research Group, Knowler WC, Fowler SE, et al. 10-Year follow-up of diabetes incidence and weight loss in the diabetes prevention program outcomes study. Lancet 2009;374:1677-86.

8 Diabetes Prevention Program Research Group. Long-Term effects of lifestyle intervention or metformin on diabetes development and microvascular complications over 15-year follow-up: the diabetes prevention program outcomes study. Lancet Diabetes Endocrinol 2015;3:866-75.

9 Wu J, Ward E, Lu ZK. Addressing lifestyle management during visits involving patients with prediabetes: NAMCS 2013-2015. J Gen Intern Med 2019;34:1412-8.
10 Shealy KM, Wu J, Waites J, et al. Patterns of diabetes screening and prediabetes treatment during office visits in the US. J Am Board Fam Med 2019;32:209-17.

11 Moin T, Li J, Duru OK, et al. Metformin prescription for insured adults with prediabetes from 2010 to 2012: a retrospective cohort study. Ann Intern Med 2015;162:542-8.

12 Tseng E, Yeh H-C, Maruthur NM. Metformin use in prediabetes among U.S. adults, 2005-2012. Diabetes Care 2017;40:887-93.

13 Okosun IS, Lyn R. Prediabetes awareness, healthcare provider's advice, and lifestyle changes in American adults. Int J Diabetes Mellit 2015;3:11-18.

14 Vazquez G, Duval S, Jacobs DR, et al. Comparison of body mass index, waist circumference, and waist/hip ratio in predicting incident diabetes: a meta-analysis. Epidemiol Rev 2007;29:115-28.

15 Bell JA, Kivimaki M, Hamer M. Metabolically healthy obesity and risk of incident type 2 diabetes: a meta-analysis of prospective cohort studies. Obes Rev 2014;15:504-15.

16 National Center for Health Statistics. Data from: National health and nutrition examination survey (2013-2018). centers for disease control and prevention.. Available: https://www.cdc.gov/nchs/nhanes/about nhanes.htm [Accessed 22 Dec 2020].

17 National Heart, Lung, and Blood Institute. Calculate your body mass index. Available: https://www.nhlbi.nih.gov/health/educational/lose wt/BMI/bmicalc.htm [Accessed 17 Aug 2021].

18 National health and nutrition examination survey: Analytic guidelines, 2011-2014 and 2015-2016. Available: https://wwwn.cdc.gov/nchs/ data/nhanes/2011-2012/analyticguidelines/analytic_guidelines_11_ 16.pdf [Accessed 17 Aug 2021].

19 Hamman RF, Wing RR, Edelstein SL, et al. Effect of weight loss with lifestyle intervention on risk of diabetes. Diabetes Care 2006;29:2102-7.

20 Tuomilehto J, Lindström J, Eriksson JG, et al. Prevention of type 2 diabetes mellitus by changes in lifestyle among subjects with impaired glucose tolerance. N Engl J Med 2001;344:1343-50.

21 Centers for Disease Control and Prevention. National diabetes education program. Available: https://www.cdc.gov/diabetes/ndep/ index.html [Accessed 14 Apr 2021].

22 Centers for Disease Control and Prevention. Hispanic/Latino Americans and type 2 diabetes. Available: https://www.cdc.gov/ diabetes/library/features/hispanic-diabetes.html [Accessed $14 \mathrm{Apr}$ 2021].

23 Mainous AG, Majeed A, Koopman RJ, et al. Acculturation and diabetes among Hispanics: evidence from the 1999-2002 National health and nutrition examination survey. Public Health Rep 2006;121:60-6.

24 Pérez-Escamilla R, Putnik P. The role of acculturation in nutrition, lifestyle, and incidence of type 2 diabetes among Latinos. J Nutr 2007;137:860-70.

25 Sorkin DH, Biegler KA, Billimek J. Differences in self-reported physical activity and body mass index among older Hispanic and non-Hispanic white men and women: findings from the 2009 California health interview survey. J Am Geriatr Soc 2015;63:2158-63.

26 Wu J, Davis-Ajami ML, Noxon V, et al. Venue of receiving diabetes self-management education and training and its impact on oral diabetic medication adherence. Prim Care Diabetes 2017;11:162-70.

27 Miller TA, DiMatteo MR. Physician-patient communication. In: Sweeny K, Robbons ML, Cohen LM, eds. The Wiley encyclopedia of health psychology. Hoboken, NJ: Wiley \& Sons, Inc, 2020: 469-5.

28 Abel S, Whitehead LC, Coppell KJ. Making dietary changes following a diagnosis of prediabetes: a qualitative exploration of barriers and facilitators. Diabet Med 2018;35:1693-9.

29 Somerville M, Ball L, Chua D, et al. How do healthcare providers support people with prediabetes to eat well? An in-depth, mixedmethods case study of provider practices. Aust J Gen Pract 2021;50:497-504.

30 Canedo JR, Miller ST, Schlundt D, et al. Racial/Ethnic disparities in diabetes quality of care: the role of healthcare access and socioeconomic status. J Racial Ethn Health Disparities 2018:5:7-14.

31 Powell PW, Corathers SD, Raymond J, et al. New approaches to providing individualized diabetes care in the 21 st century. Curr Diabetes Rev 2015;11:222-30.

32 Williams JS, Walker RJ, Smalls BL, et al. Patient-Centered care, glycemic control, diabetes self-care, and quality of life in adults with type 2 diabetes. Diabetes Technol Ther 2016;18:644-9.

33 Ali MK, Bullard KM, Saydah S, et al. Cardiovascular and renal burdens of prediabetes in the USA: analysis of data from serial cross-sectional surveys, 1988-2014. Lancet Diabetes Endocrinol 2018;6:392-403 